\title{
Old-age diversity is underrepresented in digital health research: findings from the evaluation of a mobile phone system for post-operative progress monitoring in Sweden
}

\author{
Arianna Poli ${ }^{1 \star}$ (D), Susanne Kelfve $e^{2,3}$ (D), Katarina Berg ${ }^{4}$ (D) and Andreas Motel-Klingebiel ${ }^{1}$ \\ ${ }^{1}$ Division Ageing and Social Change, Department of Culture and Society, Linköping University, \\ Norrköping, Sweden, ${ }^{2}$ Division Social Work, Department of Culture and Society, Linköping University, \\ Norrköping, Sweden, ${ }^{3}$ Aging Research Center, Karolinska Institutet and Stockholm University, Stockholm, \\ Sweden and ${ }^{4}$ Department of Health, Medicine and Caring Science, Linköping University, Linköping, \\ Sweden \\ ${ }^{*}$ Corresponding author. Email: arianna.poli@liu.se
}

(Accepted 4 October 2021)

\begin{abstract}
Much research is conducted to evaluate digital-based solutions for health-care services, but little is known about how such evaluations acknowledge diversity in later life. This study helps fill this gap and analyses participation in the evaluation of a webbased mobile phone system for monitoring the post-operative progress of patients after day surgery. Participation is conceptualised as resulting from three processes: pre-screening, recruitment and self-selection. Based on field information and survey data, this study models (a) the (non-)participation in a sample of 498 individuals aged 60 and older that includes non-screened, non-recruited, decliners and participants in the evaluation, and (b) the individual decision to participate in a sample of 210 individuals aged 60 and older who were invited to take part in the evaluation. Increasing age enhances the likelihood of not being screened, not being recruited or declining the invitation. Those not recruited were most often ineligible because of technology-related barriers. Decliners and participants differed by age, gender, job, health status, digital skills, but not by social participation. Results suggest that highly specific groups of older people are more likely to be involved than others. Old-age diversity is not properly represented in digital health research, with implications for the inclusivity of new digital health technologies. This has implications for increased risks of old-age exclusion and exacerbation of social and digital inequalities in ageing societies.
\end{abstract}

Keywords: exclusion; inequalities; digital technologies; participation in research; health; digital communication

(c) The Author(s), 2021. Published by Cambridge University Press. This is an Open Access article, distributed under the terms of the Creative Commons Attribution licence (http://creativecommons.org/licenses/by/4.0/), which permits unrestricted re-use, distribution and reproduction, provided the original article is properly cited. 


\section{Introduction}

Much effort is made to create and evaluate new solutions for delivering health care using digital health technologies. Such technologies range from websites and mobile applications to remote monitoring and rehabilitation, and are evolving continuously to reflect the latest technological advances, such as virtual and augmented reality, robotics, sensors and advances based on artificial intelligence (AI). Research shows that digital health technologies hold potential for improvements in the scope and sustainability of healthcare services' provision, ensuring quality services and acceptable individual outcomes (Schulz et al., 2015; Czaja, 2017; Chen, 2020; Corregidor-Sánchez et al., 2020). However, scholars frequently point out that although the gains of digital technologies for delivering health-care services exist, they benefit only certain groups of people and in specific contexts (Mitchell et al., 2018; Eccles, 2021).

It is widely expected that digital health technologies will be progressively used for delivering health-care services, and that older people, as the main users of health-care services in general (Terraneo, 2015), and as a key target for health-care provision by digital health technologies, are among those most affected (European Commission, 2018; Ekman et al., 2019; Mitchell and Kan, 2019; Coughlin, 2020).

With digital technologies becoming the favoured means for access to services, including health care, older people who make no or little use of digital technologies could suffer by exclusion from services and information they need or value (Olsson et al., 2019; Eccles, 2021; Poli et al., 2021). Consequently, the digitalisation of health-care services in combination with the non-use of digital technologies can increase risks of social exclusion and widen inequalities among older people (Robinson et al., 2015; Hargittai et al., 2019). This is exacerbated during the COVID-19 pandemic. Due to social and physical distancing, digitalisation of services becomes a priority measure (Pérez Sust et al., 2020; Seifert, 2020).

Previous studies suggest that the use of digital technologies among older people varies by individual characteristics such as age, gender, education and work, and prior experience with such technologies (e.g. at work) (König et al., 2018; Yoon et al., 2018; Hargittai et al., 2019; Matthews et al., 2019). Non-use can also result from an individual decision not to engage with digital technologies or to use certain technologies but not others (Wyatt, 2003; Lüders and Brandtzæg, 2014; Gallistl et al., 2020), privacy concerns (Boise et al., 2013; Berridge and Wetle, 2019; Kim and Choi, 2019) as well as poor health status (Gell et al., 2015; Matthews et al., 2019). Moreover, digital technology use and non-use can be influenced by the design of new technological solutions which may support or hinder adoption by older people (Czaja et al., 2019; Allemann and Poli, 2020). However, the design is not the only factor determining the inclusivity of digital technologies and new digital-based services. Aspects related to the evaluation of new digital technologies, such as how this is conducted and who is involved as participants, are also crucial for ensuring accessibility, usage and utility (Merkel and Kucharski, 2018; Poli et al., 2019).

Due to selective participation in the evaluations of new digital technologies, digital health research often fails to capture the heterogeneity of the target populations of interest (Czaja, 2017; Merkel and Kucharski, 2018). Selective participation is established during the recruitment process of study participants through three 
successive selection processes, namely pre-screening, recruitment and self-selection. As a result, some individuals have a higher probability of participating in evaluations than others (Dodge et al., 2014; Foster et al., 2015; Poli et al., 2019, 2020). The underrepresentation of some individuals can affect the evaluations as it prevents the assessment of the appropriateness of new digital health technologies against the heterogeneity of the target population, and leads to erroneous conclusions and inadequate implementation (Aner, 2016; Czaja, 2017; Kandola et al., 2018; Merkel and Kucharski, 2018).

The process of self-selection refers to the decision to, or not to, accept an invitation to participate in research, made by those individuals who are deemed eligible for participation (Baron et al., 2015; Poli et al., 2019). Of the other selection processes occurring during the recruitment of participants, self-selection is especially relevant as it typically implies that a number of individuals are left out. Previous studies reported that refusal rates can range from 50 per cent to more than 80 per cent (Dodge et al., 2014; Foster et al., 2015; Broendum et al., 2016; Poli et al., 2020). Self-selection shapes the composition of the study participants, is almost not possible to directly control and determines the extent to which a study sample mirrors the targeted population of interest.

Only a small number of studies on digital health technologies have investigated self-selection among older people. They suggest that those who decline to participate are older, less physically active and less often users of a computer than those who join (Mair et al., 2006; Dodge et al., 2014; Broendum et al., 2016; Poli et al., 2020). Findings on health status are mixed. One study reports a higher hospital admission rate among decliners (Broendum et al., 2016), whereas significant differences in health status were not found in another study (Poli et al., 2020). Results on gender are also inconclusive, with some studies suggesting that women are more likely to decline the invitation to participate in research on digital health technologies (Broendum et al., 2016) while other studies find no differences between men and women (Mair et al., 2006; Dodge et al., 2014; Poli et al., 2020). Lack of time, discomfort with technologies and satisfaction with current services are reported as the most common reasons for declining (Mair et al., 2006; Broendum et al., 2016; Poli et al., 2019). Overall, these studies are typically based on recruitment information only (e.g. reasons for refusal, registry-based or hospital data), or investigate self-selection as an one-off selection process rather than as part of a sequence of selection processes in the study participant recruitment.

A deeper understanding of the self-selection process among older people in digital health research is needed to inform on the inclusiveness of such studies and the generalisability of the results, and to guide both the optimisation of recruitment strategies and the implementation of sample or result adjustments (Poli et al., 2019). To the best of our knowledge, no studies have conducted a detailed investigation of self-selection among older people which takes into account the individual perspective on participation and non-participation and, at the same time, interprets self-selection as part of a multi-step model of selection leading to selective participation (Poli et al., 2019).

In this article, we aim to understand the involvement of older people in the evaluation of digital health technologies for self-care as a multi-step process from project recruitment to the individuals' decisions to participate (i.e. self-selection) 
and its association with socio-demographic indicators, health, social participation and technology familiarity. Our example is participation in the evaluation of a Web-based mobile phone system for monitoring post-operative progress of patients undergoing day surgery. The underlying data were collected in Sweden which is one of the most digitally advanced countries in Europe (European Commission, 2020) and, hence, an exemplifying case of likely future conditions in other European societies. In 2019, 98 per cent of the population in Sweden indicated having access to the internet at home; 10 per cent of Swedes between 65 and 74 years and a third of the individuals in the 75-85 years group reported that they had never used the internet (Statista, 2021). First, we analyse the selection of participants by applying a multi-step conceptual model for the study of selective participation which deconstructs the latter in all its processes of selection as elaborated and detailed by Poli et al. (2019). Second, we deepen the analysis of the self-selection to interpret the basis of the individual decision to participate or not. We hypothesise that higher age, low socio-economic status, poor health, low frequency of social participation as well as lower digital skills are associated with the likelihood of declining an invitation to participate in the evaluation.

\section{Methods}

Analysed data were gathered in 2018 within the context of the project 'Mobile Phone in Recovery after Ambulatory Surgery' (MIRAS) which evaluated a webbased mobile phone system for monitoring post-operative progress of individuals who underwent day surgery.

The MIRAS intervention study was designed as a randomised controlled trial (RCT). Eligible individuals were consecutively included and randomised either to post-operative monitoring through their mobile phone (i.e. the intervention group) or to traditional post-operative monitoring at the day surgery unit (i.e. the control group). Individuals in the intervention group were invited to answer short questions on their recovery progress online using their mobile phones on days $1-14,21$ and 28 . The collected information was stored in a highly secured, password-protected database which was accessible only to the patient and the responsible health-care professional. Individuals in the control group were monitored according to the surgery units' routines. Both individuals in the intervention and control groups were asked to answer a paper-based questionnaire on the day of the surgery and received a further paper-based questionnaire assessing key aspects of their recovery on the postoperative day 28 . The allocation to intervention group or control group and the related types of interventions were not relevant to this work and its analyses, as the interest is on the MIRAS participants in general, regardless of the study groups to which they belong, and on the non-participants.

MIRAS recruitment was conducted at two Swedish public day surgery units in the cities of Linköping and Motala. The MIRAS target population consisted of individuals undergoing day surgery in the fields of orthopaedics, general surgery including breast cancer, and urology. To be eligible to take part in the MIRAS project, individuals had to meet the following criteria: (a) have a mobile phone equipped with internet connection, (b) be able to speak Swedish, (c) not show/ report other health problems which could interfere with the intervention (e.g. 
aphasia, dementia), and (d) be older than 18. The MIRAS project received ethical approval from the competent Regional Ethical Review Board in Linköping.

In addition to the intervention study, an investigation of the involvement of older people in the evaluation of the MIRAS mobile phone system was conducted, also by means of a survey study (Poli et al., 2019). MIRAS intervention outcomes were not of interest for this work which looked at the phases that precede the intervention, i.e. the selection of participants.

\section{Data}

The sample for the present study consists of all individuals, 60 years and older, who were scheduled for the above-mentioned day surgeries in the two units during the recruitment time-frame of the MIRAS project. As such, this sample includes both those individuals who entered the MIRAS recruitment process and those who did not due to non-eligibility.

This study sample consists of 498 individuals in total. The mean age of the individuals in the sample is 70 years (standard deviation $(\mathrm{SD})=0.32$ ); the median age is also 70 years, where about a quarter of the individuals are aged 60-64 and 65-69 years $(\mathrm{N}=120$ and $\mathrm{N}=119$, respectively). Of the 498 individuals, one-third are men $(\mathrm{N}=168)$ and two-thirds are women $(\mathrm{N}=330)$ (Table 1$)$.

Information on the study sample was obtained from two sources: recruitment data and individual survey data. Recruitment data include information on age, gender and recruitment status for all the individuals in the study sample $(\mathrm{N}=498)$, and detailed information on reasons for non-recruitment for the 58 individuals who were not recruited.

Individuals considered eligible and, thus, invited to participate in the MIRAS project, were also invited to answer a short questionnaire that included questions on socio-demographic factors, social participation and contacts, as well as health-related aspects and technology familiarity (more details on the survey, its items and validation can be found in Poli et al. (2019). This sub-group consists of 368 individuals, of whom 160 participated in MIRAS and 208 were decliners. The survey was distributed by a research nurse at the time of the invitation to the MIRAS project on the day of surgery and collected on the same day. In total, 210 individuals answered the questionnaire (response rate $=57 \%$ ), including all MIRAS participants (response rate $=100 \%$ ) and 50 MIRAS decliners (response rate $=24 \%)$.

\section{The self-selection analysis}

In this study, the individual decision-making process of accepting or declining the invitation to take part in the research (i.e. self-selection) was examined as a selection process occurring during the recruitment of study participants that distinguished between decliners (i.e. non-participants) and participants. First, the overall selection of participants was studied as a multi-step process (Poli et al., 2019, 2020) and, second, self-selection was specifically analysed for its association with key indicators. 


\begin{tabular}{|c|c|c|c|c|c|c|c|c|}
\hline & \multirow[b]{2}{*}{ Total } & \multicolumn{4}{|c|}{ Recruitment groups } & \multirow[b]{2}{*}{$\chi^{2}$} & \multirow[b]{2}{*}{$F$} & \multirow[b]{2}{*}{$p$} \\
\hline & & Non-screened & Non-recruited & Decliner & Participant & & & \\
\hline \multicolumn{9}{|c|}{ Frequencies (row percentages) } \\
\hline Group size & $498(100)$ & $72(14.5)$ & $58(11.6)$ & $208(41.8)$ & $160(32.1)$ & & & \\
\hline \multicolumn{9}{|c|}{ Group characteristics: } \\
\hline Age group: & & & & & & 60.43 & & $0.000^{* \star \star}$ \\
\hline $60-64$ & $120(24)$ & $13(11)$ & $5(4)$ & $45(38)$ & $57(47)$ & & & \\
\hline $65-69$ & $119(24)$ & $15(13)$ & $7(6)$ & $54(45)$ & $43(36)$ & & & \\
\hline $70-74$ & $133(27)$ & $21(16)$ & $13(10)$ & $55(41)$ & $44(33)$ & & & \\
\hline $75+$ & $126(25)$ & $23(18)$ & $33(26)$ & $54(43)$ & $16(13)$ & & & \\
\hline Mean age (SD) & $70(0.32)$ & $71(0.82)$ & $76(1.09)$ & $70(0.48)$ & $67(0.44)$ & & 23.46 & $0.000^{\star \star \star}$ \\
\hline Gender: & & & & & & 12.84 & & $0.005^{\star \star}$ \\
\hline Men & $168(34)$ & $34(20)$ & $24(14)$ & $70(42)$ & $40(24)$ & & & \\
\hline Women & $330(66)$ & $38(12)$ & $34(10)$ & $138(42)$ & $120(36)$ & & & \\
\hline
\end{tabular}


We used the multi-step conceptual model of selective non-participation illustrated in Poli et al. (2019) which here includes three processes of selection, namely pre-screening, recruitment and self-selection. In pre-screening, some individuals are screened out prior to any formal eligibility check and for no documented reasons. In the recruitment, proper screening and eligibility checks are conducted and result in eligible and ineligible individuals. In self-selection, individuals choose whether they want to be included or not. Self-selection together with pre-screening and recruitment lead to a four-group structure: a non-screened group (which was excluded prior to screening), a non-recruited group (which was screened, but not recruited), a decliner group (which was screened and recruited but declined to participate) and a participant group, which consists of those who were screened and recruited and who decided to participate. In the study sample, the participant group represented 32 per cent $(\mathrm{N}=160)$ (Table 1$)$. Over 40 per cent $(\mathrm{N}=208)$ of the individuals declined to participate, 12 per cent $(\mathrm{N}=58)$ were not recruited due to ineligibility and 14 per cent $(\mathrm{N}=72)$ were excluded prior to being screened (i.e. non-screened group). The refusal rate (i.e. the decliners as a percentage of all individuals invited to participate) to the MIRAS project was 56 per cent $(\mathrm{N}=208)$, the non-screened rate (i.e. the non-screened individuals as a percentage of all the individuals who underwent an eligible day surgery) was 14 per cent $(\mathrm{N}=72)$ and the non-recruitment (i.e. the non-recruited individuals as a percentage of everyone who was screened) rate was 14 per cent $(\mathrm{N}=58)$.

\section{Outcome variables}

Two main outcome variables were used: 'recruitment group' and 'self-selection'.

The 'recruitment group' was constructed as a categorical variable which took on four categories corresponding to the four recruitment groups of which individuals could alternatively be part (i.e. non-screened, non-recruited, decliner and participant). The outcome variable 'self-selection' was constructed as a binary variable (i.e. refusal/participation).

\section{Predictors}

The level of education is measured by the International Standard Classification of Education, and the analyses apply two levels of education: 'lower' (i.e. up to 13 years of education) and 'higher' (i.e. more than 13 years of education). Occupational position is measured as: 'white-collar jobs' and 'other positions', while cases with missing information $(\mathrm{N}=25)$ are included in a third category. Due to the low number of cases, we collapsed farmers, self-employed and blue-collar jobs into the category 'other positions'. This allows a clear contrast to be created between the 'white-collar jobs' category and the rest. Partnership and co-habitation are combined in a single variable and coded as 'having a partner and co-habiting' and 'other constellations'. Overall health, cognitive health and instrumental activities of daily living are combined in a single indicator 'physical and cognitive health': 'better' (based on 'good' or 'very good' overall health, 'good' or 'very good' cognitive health and 'not limited at all') and 'poorer' (all the other combinations). 
Social participation, contacts with friends and neighbours, and contacts with children are aggregated in a single indicator, 'social participation and contacts', and coded as 'higher frequency' ('every week' or 'daily' participation in social activities and 'daily' contacts with either children or friends, or both) and 'lower frequency' (all other combinations).

Digital skills were defined in this work as the range of abilities and knowledge to use digital services and measured as self-rated skills in using and accessing digital services (i.e. sending and receiving emails, internet banking, reading online newspapers or magazines, buying goods or services over the internet, accessing public e-services). These form a single indicator and are coded as 'higher' (i.e. average answer was 'very good' in all the relevant items on digital skills) and 'lower' (i.e. for all the other combinations). The perceived usefulness of using technologies for health monitoring was defined as the degree to which an individual believes that using a certain digital health technology would be beneficial for him- or herself and was measured by a single item (i.e. 'Do you think using a mobile phone or tablet might be useful in monitoring your health?') as 'high' and 'low'. Analyses control for age group and gender. Age is a categorical variable (60-64, 65-69, 70-74, and 75 years and over) to take into account non-linear relationships, while gender is applied as a binary category.

Missing information on any of these predictors is shown in Table 4, but is not computed in the group comparisons. Because missing values on each predictor represented a small percentage of the cases which are irrelevant for imputation, too small for a separate missing category, and typically considered as inconsequential for the results (Schafer, 1999; Bennett, 2001), missing information is merged into the largest variable category for the logistic regression analyses. The variable on occupational status is an exception as the item non-response is about 12 per cent and could not be assigned to another category of the variable; therefore, missing data were treated by creating a third category representing the missingness. This allowed the potential impact of missing data on the association between the predictor and the outcome to be isolates. There is no missing information for age group and gender.

\section{Analyses}

First, the overall selection of study participants is analysed based on the multi-step conceptual model for the study of selective non-participation as originally developed by Poli et al. (2019) and extended with a further process of selection (i.e. prescreening). Age and gender differences between the four groups: non-screened, non-recruited, decliner and participant, are tested using Pearson's chi-squared tests and one-way analysis of variance. Participation and non-participation rates are calculated for each of the four groups based on the respective sub-samples. This means that, for example, the refusal rate represents the proportion of those who declined to participate among all those invited. Moreover, a multinomial logistic regression was estimated to describe the differences between participants and non-participants (i.e. non-screened, non-recruited and decliner) regarding age and gender. Finally, the analyses of the reasons for non-recruitment were added to further explain the selection of individuals. 
Second, the analysis of self-selection is deepened. Descriptive statistics are performed to show how socio-demographic indicators, health, social participation and technology familiarity characterise decliners and participants. Pearson's chi-squared tests and Student's $t$-test are used to test differences between decliners and participants. In addition, four logistic regression models were developed in order to investigate the association between the individual decision to decline (or not) the invitation to participate in the MIRAS project and the identified predictors. Model 1 includes three socio-demographic indicators (i.e. age, gender and main job). Thereafter, all dimensions (health, social participation and contacts, and digital skills), each of them represented by one single indicator, are included stepwise into the models. The reference category for all models is 'participation'. All analyses are performed using Stata 15 (StataCorp, College Station, TX).

\section{Results}

\section{Descriptive results}

Mean age was significantly different between the four analysed groups (i.e. non-screened, non-recruited, decliners and participants) (Table 1). Participants were significantly younger $(67$ years, $\mathrm{SD}=0.44)$ and non-recruited individuals were significantly older $(76$ years, $\mathrm{SD}=1.09)$ than the individuals in the non-screened and decliner groups (71 years, $\mathrm{SD}=0.82$ and 70 years, $\mathrm{SD}=0.48$, respectively) $(p<0.001)$.

Participation was lowest among individuals 75 years old and older $(13 \%, \mathrm{~N}=16)$ and highest among individuals aged 60-64 (47\%, $\mathrm{N}=57)(p<0.001)$. Individuals 75 years and older were significantly more often non-screened $(18 \%, \mathrm{~N}=23)$ and non-recruited $(26 \%, \mathrm{~N}=33)$ than those who were aged $60-64(11 \%, \mathrm{~N}=13$ and $4 \%, \mathrm{~N}=5), 65-69(13 \%, \mathrm{~N}=15$ and $6 \%, \mathrm{~N}=7)$ and $70-74(16 \%, \mathrm{~N}=21$ and $10 \%, \mathrm{~N}=13)(p<0.001)$. Declining the invitation to participate in the MIRAS project was significantly more common among individuals 65-69 years and 75 years and older, respectively 45 per cent $(\mathrm{N}=54)$ and 43 per cent $(\mathrm{N}=54)$, compared to $60-64(38 \%, \mathrm{~N}=45)$ and $70-74$ years old $(41 \%, \mathrm{~N}=55)$ $(p<0.001)$.

On average, it was significantly more common for women to participate $(36 \%$, $\mathrm{N}=120)$ compared to men $(24 \%, \mathrm{~N}=40)$. Men were more often not screened $(20 \%, \mathrm{~N}=34)$ and not recruited $(14 \%, \mathrm{~N}=24)$ than women $(12 \%, \mathrm{~N}=38$ and $10 \%, \mathrm{~N}=34$, respectively) $(p<0.05)$.

\section{(Non-)Participation in the MIRAS project}

The multinomial logistic regression model shows that age and gender were associated with the likelihood of being or not being a participant in the MIRAS project (Table 2). Age significantly predicted the likelihood of participating for individuals 75 years old and older. Indeed, individuals in this age group showed a higher probability of being non-screened (odds ratio $(\mathrm{OR})=3.80, p<0.05)$, non-recruited (OR $=12.09, p<0.001)$ and a decliner $(\mathrm{OR}=2.61, p<0.05)$ than of being a participant in the MIRAS project, compared to individuals aged 65-69. As regards gender, 


\begin{tabular}{|c|c|c|c|c|c|c|c|c|c|c|c|c|}
\hline & \multicolumn{4}{|c|}{$\begin{array}{l}\text { Non-screened group versus participant } \\
\text { group }^{1}\end{array}$} & \multicolumn{4}{|c|}{ Non-recruited group versus participant group ${ }^{1}$} & \multicolumn{4}{|c|}{ Decliner group versus participant group ${ }^{1}$} \\
\hline & OR & SE & $p$ & $95 \% \mathrm{Cl}$ & OR & SE & $p$ & $95 \% \mathrm{Cl}$ & OR & SE & $p$ & $95 \% \mathrm{Cl}$ \\
\hline Intercept & 0.62 & 0.22 & 0.181 & $0.31,1.25$ & 0.23 & 0.11 & 0.002 & $0.09,0.59$ & 1.59 & 0.43 & 0.086 & $0.94,2.69$ \\
\hline \multicolumn{13}{|l|}{ Age group: } \\
\hline $60-64$ & 0.69 & 0.30 & 0.383 & $0.29,1.60$ & 0.55 & 0.34 & 0.340 & $0.16,1.87$ & 0.64 & 0.18 & 0.117 & $0.36,1.12$ \\
\hline $\begin{array}{l}\text { 65-69 } \\
\text { (Ref.) }\end{array}$ & 1.00 & - & - & - & 1.00 & - & - & - & 1.00 & - & - & - \\
\hline $70-74$ & 1.30 & 0.52 & 0.518 & $0.59,2.87$ & 1.76 & 0.91 & 0.273 & $0.64,4.85$ & 0.98 & 0.28 & 0.937 & $0.56,1.72$ \\
\hline $75+$ & 3.80 & 1.70 & $0.003^{* *}$ & $1.58,9.11$ & 12.09 & 6.17 & $0.000^{\star \star \star}$ & $4.45,32.87$ & 2.61 & 0.92 & $0.006^{\star \star}$ & $1.31,5.20$ \\
\hline \multicolumn{13}{|l|}{ Gender: } \\
\hline $\begin{array}{l}\text { Men } \\
\text { (Ref.) }\end{array}$ & 1.00 & - & - & - & 1.00 & - & - & - & 1.00 & - & - & - \\
\hline Women & 0.42 & 0.13 & $0.005^{\star \star}$ & $0.23,0.77$ & 0.60 & 0.21 & 0.138 & $0.31,1.18$ & 0.72 & 0.17 & 0.176 & $0.45,1.16$ \\
\hline
\end{tabular}

Table 2. Multinomial logistic regression on the association between (non-)participation and age and gender

Notes: McFadden's pseudo $R^{2}=0.05$. 1. The reference category (Ref.) is participant group. OR: odds ratio. SE: standard error. Cl: confidence intervals. Significance levels: ${ }^{\star} p \leqslant 0.05,{ }^{\star \star} p \leqslant 0.01,{ }^{\star \star \star} p \leqslant 0.001$. 
Table 3. Registered reasons for non-recruitment by age

\begin{tabular}{lccccc}
\hline & & \multicolumn{4}{c}{ Age groups } \\
\cline { 3 - 6 } Reasons for non-recruitment $^{1}$ & Total & $60-64$ & $65-69$ & $70-74$ & $75+$ \\
\hline & & & Frequencies (percentages) \\
\hline Technology-related & 42 & $1(2)$ & $4(10)$ & $9(21)$ & $28(67)$ \\
\hline Language-related & 9 & $2(22)$ & $2(22)$ & $2(22)$ & $3(33)$ \\
Health-related & 8 & $2(25)$ & $2(25)$ & $2(25)$ & $2(25)$ \\
\hline
\end{tabular}

Notes: $\mathrm{N}=59$. 1 . Individuals could be deemed ineligible for more than one reason.

women had a lower probability of being non-screened than men, relative to being a participant in the MIRAS project $(\mathrm{OR}=0.42, p<0.05)$.

Among the 58 individuals who were screened and non-recruited, the most reported reason for ineligibility to the MIRAS project was related to one eligibility criterion, namely to one's mobile phone availability or appropriateness (Table 3). This criterion included, for example, not having a mobile phone, having a faulty or too old mobile phone, and not having an internet access subscription, and was indicated for 42 individuals. Of these 42 individuals, 67 per cent $(\mathrm{N}=28)$ were 75 years old or older and 21 per cent $(\mathrm{N}=9)$ were $70-74$. Non-recruitment due to technology-related barriers was less common among those aged $60-64$ and $65-69,2$ per cent $(\mathrm{N}=1)$ and 10 per cent $(\mathrm{N}=4)$, respectively. The other two reasons for non-recruitment were related to language barriers and health problems. A total of nine individuals were not recruited because they could not speak fluent Swedish (60-64 years old: $22 \%, \mathrm{~N}=2 ; 65-69$ years old: $22 \%, \mathrm{~N}=2 ; 70-74$ years old: $22 \%, \mathrm{~N}=2 ; 75$ years old and older: $33 \%, \mathrm{~N}=$ 3). Eight individuals (60-64 years old: $25 \%, \mathrm{~N}=2 ; 65-69$ years old: $25 \%, \mathrm{~N}=2$; 70-74 years old: $25 \%, \mathrm{~N}=2 ; 75$ years old and older: $25 \%, \mathrm{~N}=2$ ) were deemed not eligible for participation because of comorbidity (e.g. aphasia, dementia, memory impairments).

\section{Self-selection in the MIRAS project}

Self-selection was studied for 50 decliners and 160 participants who participated in the survey study. The decision to participate or not in the MIRAS evaluation phase was interpreted for its association with socio-demographic aspects, social participation and contacts, health-related aspects, and technology familiarity.

\section{Socio-demographic characteristics}

Those who participated in the MIRAS project were significantly younger than the decliners (mean $=67, \mathrm{SD}=0.44$ versus mean $=70, \mathrm{SD}=0.48) \quad(p<0.05)$ (Table 4$)$. Individuals in the age group 60-64 were significantly more often participants $(88 \%, \mathrm{~N}=57)$ compared to individuals in the older age groups $(65-69$ years old: $73 \%, \mathrm{~N}=43 ; 70-74$ years old: $76 \%, \mathrm{~N}=44 ; 75$ years old or older: 
Table 4. Decliners and participants comparison

\begin{tabular}{|c|c|c|c|c|c|c|}
\hline & \multirow[b]{2}{*}{ Total } & \multicolumn{2}{|c|}{ Self-selection } & \multirow[b]{2}{*}{$\chi^{2}$} & \multirow[b]{2}{*}{$t$} & \multirow[b]{2}{*}{$p$} \\
\hline & & Decliner group ${ }^{1}$ & Participant group & & & \\
\hline \multicolumn{7}{|c|}{ Frequencies (row percentages) } \\
\hline Group size & $210(100)$ & $50(24)$ & $160(76)$ & & & \\
\hline \multicolumn{7}{|l|}{ Group characteristics: } \\
\hline \multicolumn{7}{|l|}{ Age group: } \\
\hline $60-64$ & $65(100)$ & $8(12)$ & $57(88)$ & 10.70 & & $0.013^{\star}$ \\
\hline $65-69$ & $59(100)$ & $16(27)$ & $43(73)$ & & & \\
\hline $70-74$ & $58(100)$ & $14(24)$ & $44(76)$ & & & \\
\hline $75+$ & $28(100)$ & $12(43)$ & $16(57)$ & & & \\
\hline Mean age (SD) & $68(0.40)$ & $70(0.48)$ & $67(0.44)$ & & -2.99 & $0.003^{\star \star}$ \\
\hline \multicolumn{7}{|l|}{ Gender: } \\
\hline Men & $66(100)$ & $26(39)$ & $40(61)$ & 12.89 & & $0.000^{\star \star *}$ \\
\hline Women & $144(100)$ & $24(17)$ & $120(83)$ & & & \\
\hline \multicolumn{7}{|l|}{ Education: } \\
\hline Lower & $100(100)$ & $30(30)$ & $70(70)$ & 3.75 & & 0.053 \\
\hline Higher & $108(100)$ & $20(19)$ & $88(81)$ & & & \\
\hline Missing $^{2}$ & 2 & 0 & 2 & & & \\
\hline \multicolumn{7}{|l|}{ Main job: } \\
\hline Other positions ${ }^{3}$ & $106(100)$ & $32(30)$ & $74(70)$ & 4.83 & & 0.089 \\
\hline White-collar jobs & $79(100)$ & $14(18)$ & $65(82)$ & & & \\
\hline Missing $^{2}$ & $25(100)$ & $4(16)$ & $21(84)$ & & & \\
\hline
\end{tabular}




\begin{tabular}{|c|c|c|c|c|c|}
\hline \multicolumn{6}{|l|}{ Partnership and co-habitation: } \\
\hline Other constellations & $54(100)$ & $12(22)$ & $42(78)$ & 0.08 & 0.784 \\
\hline Having a partner and co-habitation & $151(100)$ & $35(23)$ & $116(77)$ & & \\
\hline Missing $^{2}$ & 5 & 3 & 2 & & \\
\hline \multicolumn{6}{|l|}{ Social participation and contacts: } \\
\hline Lower frequency & $161(100)$ & $39(24)$ & $122(76)$ & 0.18 & 0.675 \\
\hline Higher frequency & $47(100)$ & $10(21)$ & $37(79)$ & & \\
\hline Missing ${ }^{2}$ & 2 & 1 & 1 & & \\
\hline \multicolumn{6}{|l|}{ Physical and cognitive health: } \\
\hline Poorer & $130(100)$ & $39(30)$ & $91(70)$ & 7.75 & $0.005^{\star *}$ \\
\hline Better & $77(100)$ & $10(13)$ & $67(87)$ & & \\
\hline Missing ${ }^{2}$ & 3 & 1 & 2 & & \\
\hline \multicolumn{6}{|l|}{ Digital skills: } \\
\hline Lower & $118(100)$ & $36(31)$ & $82(69)$ & 7.10 & $0.008^{\star \star}$ \\
\hline Higher & $89(100)$ & $13(15)$ & $76(85)$ & & \\
\hline Missing $^{2}$ & 3 & 1 & 2 & & \\
\hline \multicolumn{6}{|l|}{$\begin{array}{l}\text { Perceived usefulness of } \\
\text { health-monitoring technologies: }\end{array}$} \\
\hline Low & $148(100)$ & $41(28)$ & $107(72)$ & 4.74 & $0.029^{*}$ \\
\hline High & $54(100)$ & $7(13)$ & $47(87)$ & & \\
\hline Missing $^{2}$ & 8 & 2 & 6 & & \\
\hline
\end{tabular}

Notes: 1 . This group only includes those who answered the survey (i.e. 50 individuals out of 208). 2. Missing cases were not computed in the chi-squared analyses, except for the variable 'main job' for which the missing cases represented a large proportion of cases. 3. This category collapses farmers, self-employed and blue-collar jobs. SD: standard deviation.

Significance levels: ${ }^{*} p \leqslant 0.05,{ }^{\star \star} p \leqslant 0.01,{ }^{\star \star \star} p \leqslant 0.001$. 
$57 \%, \mathrm{~N}=16)(p<0.05)$. Moreover, individuals 75 years old and older were more often decliners $(43 \%, \mathrm{~N}=12)$ compared to individuals $60-64$ years old $(12 \%, \mathrm{~N}=8), 65-69$ years old $(27 \%, \mathrm{~N}=16)$ and $70-74$ years old $(24 \%, \mathrm{~N}=$ 14) $(p<0.05)$.

Men and women differed significantly regarding their decision to participate. Women declined less often and participated more often than men (decliners: $17 \%, \mathrm{~N}=24$ and $39 \%, \mathrm{~N}=26$, respectively; participants: $83 \%, \mathrm{~N}=120$ and $61 \%$, $\mathrm{N}=40$, respectively) $(p<0.01)$.

Individuals who indicated they have white-collar jobs seemed to more often accept taking part in the MIRAS evaluation $(82 \%, \mathrm{~N}=65)$ compared to those individuals who reported other job positions $(70 \%, \mathrm{~N}=74)$, but this difference was not statistically significant in our study.

\section{Social participation and contacts}

Individuals who reported a higher frequency of social participation and contacts seemed to participate slightly more often $(79 \%, \mathrm{~N}=37)$ and to decline less often $(21 \%, \mathrm{~N}=10)$ than individuals who reported a lower frequency of social participation and contacts (decliners: $76 \%, \mathrm{~N}=122$; participants: $79 \%, \mathrm{~N}=37$ ). However, these differences were not statistically significant.

\section{Health-related aspects}

Individuals who indicated a better health status and those with a poorer health status differed significantly with regards to their decision to participate $(p<0.05)$. Participating in the MIRAS evaluation was significantly more common among those indicated to have a better health status $(87 \%, \mathrm{~N}=67)$ than among those with poorer health status $(70 \%, \mathrm{~N}=91)(p<0.05)$. Those with a better health status were significantly less often decliners $(13 \%, \mathrm{~N}=10)$ than those with poorer health status $(30 \%, \mathrm{~N}=39)(p<0.05)$.

\section{Technology familiarity}

Individuals who reported having higher digital skills accepted the invitation to participate significantly more often compared to individuals with lower self-reported digital skills ( $85 \%, \mathrm{~N}=76$ and $69 \%, \mathrm{~N}=82$, respectively) $(p<0.05)$. It was more common for individuals with lower digital skills to decide not to participate $(31 \%, \mathrm{~N}=36)$ compared to their counterparts $(15 \%, \mathrm{~N}=13) \quad(p<0.05)$. Moreover, accepting the invitation to participate was significantly more common among those individuals who agreed that health-monitoring technologies are useful $(87 \%, \mathrm{~N}=47)$ compared to those who did not believe this $(72 \%, \mathrm{~N}=107)(p<$ $0.05)$; and, it was more common among individuals who reported lower perceived usefulness of health-monitoring technologies to decline $(28 \%, \mathrm{~N}=41)$ compared to the group which reported higher perceived usefulness of such technologies $(13 \%, \mathrm{~N}$ $=7)(p<0.05)$. 


\section{Modelling the self-selection of the MIRAS project}

We tested a model of self-selection depending on six predictors. The predictors were included in a stepwise manner in order to understand how they work together. This generated four models in total. Overall, the final model (i.e. Model 4) shows that those in younger age groups, women, with better health status and with higher digital skills had a lower likelihood of declining the invitation to participate in the MIRAS project $(\mathrm{OR}=0.36, p<0.05 ; \mathrm{OR}=0.30, p<0.05 ; \mathrm{OR}=0.43$, $p<0.05$; OR $=0.39, p<0.05$, respectively) and thus participated more often, compared to those in older age groups, men, with poorer health status and with lower digital skills (Table 5).

As a first step, we tested a model which focused on the association between the individual decision-making process regarding participation and sociodemographic aspects which included age, gender, and current or latest main job (i.e. Model 1). It reveals that women were significantly less likely to decline than to be participants in the MIRAS project $(\mathrm{OR}=0.31, p<0.05)$ compared to men. Also, individuals in white-collar jobs showed a lower likelihood of being decliners than being participants, compared to individuals in other job positions $(\mathrm{OR}=0.44, p<0.05)$.

In Model 2, frequency of social participation and contacts was added. Frequency of social participation and contacts was not significantly associated to the likelihood of declining to participate and did not contribute to the explained variance. Both the OR values and the McFadden's pseudo $R^{2}$ are similar in Models 1 and 2.

In Model 3, a measure of physical and cognitive health was added. The model shows that health significantly contributed to the decision to participate or not in the MIRAS project. Those who reported better physical and cognitive health were less likely to decline the invitation to participate in the MIRAS project compared to those who indicated a poorer health status $(\mathrm{OR}=0.42, p<0.05)$. This also resulted in a slight decrease in declining differences by gender (Model 2: OR = 0.32 versus Model 3: $\mathrm{OR}=0.34$ ). Also, the effect of job status on the decision to participate loses significance after introducing the health variable into the model.

As a last step, self-reported level of digital skills was included to test the final model of self-selection based on the six predictors, i.e. Model 4. Model 4 shows that the level of digital skills was significantly associated with the decision to decline or not to participate in the MIRAS project. Reporting a higher level of digital skills significantly decreased the likelihood of declining $(\mathrm{OR}=0.39, p<0.05)$, compared to indicating lower digital skills. Adding digital skills to the model resulted in a further decrease in the effect of job on the decision to decline (Model 3: OR $=0.49$; Model 4: $\mathrm{OR}=0.62$ ) which is not significant and showed an effect of age. Individuals in the age group 60-64 were less likely to decline to participate in the MIRAS evaluation than individuals aged 65-69 (OR=0.36, $p<0.05)$. There was an increment in the pseudo $R^{2}$ value in each successive model, with Model 4 showing the best fit compared to the previous models (McFadden's pseudo $\left.R^{2}=0.16\right)$. 
Table 5. Regression models on the decision to participate or not in the MIRAS project

\begin{tabular}{|c|c|c|c|c|c|c|c|c|c|c|c|c|c|c|c|c|}
\hline & \multicolumn{4}{|c|}{ Model $1^{1}$} & \multicolumn{4}{|c|}{ Model $2^{1}$} & \multicolumn{4}{|c|}{ Model $3^{1}$} & \multicolumn{4}{|c|}{ Model $4^{1}$} \\
\hline & OR & SE & $p$ & $95 \% \mathrm{Cl}$ & OR & SE & $p$ & $95 \% \mathrm{Cl}$ & OR & SE & $p$ & $95 \% \mathrm{Cl}$ & OR & SE & $p$ & $95 \% \mathrm{Cl}$ \\
\hline Intercept & 1.11 & 0.45 & 0.800 & $0.50,2.44$ & 1.14 & 0.47 & 0.741 & $0.51,2.55$ & 1.41 & 0.60 & 0.421 & $0.61,3.24$ & 2.11 & 0.99 & 0.11 & $0.84,5.29$ \\
\hline \multicolumn{17}{|l|}{ Age: } \\
\hline $60-64$ & 0.38 & 0.19 & 0.051 & $0.14,1.00$ & 0.37 & 0.19 & $0.048^{\star}$ & $0.14,0.99$ & 0.37 & 0.19 & 0.051 & $0.14,1.01$ & 0.36 & 0.18 & $0.045^{\star}$ & $0.13,0.98$ \\
\hline 65-69 (Ref.) & 1.00 & & & & 1.00 & & & & 1.00 & & & & 1.00 & & & \\
\hline $70-74$ & 0.85 & 0.38 & 0.715 & $0.36,2.03$ & 0.85 & 0.38 & 0.706 & $0.35,2.02$ & 0.79 & 0.34 & 0.6 & $0.32,1.92$ & 0.75 & 0.34 & 0.537 & $0.31,1.85$ \\
\hline $75+$ & 2.05 & 1.03 & 0.155 & $0.76,5.49$ & 2.11 & 1.07 & 0.142 & $0.78,5.72$ & 1.99 & 1.02 & 0.18 & $0.73,5.45$ & 1.63 & 0.86 & 0.357 & $0.58,4.57$ \\
\hline \multicolumn{17}{|l|}{ Gender: } \\
\hline Men (Ref.) & 1.00 & & & & 1.00 & & & & 1.00 & & & & 1.00 & & & \\
\hline Women & 0.31 & 0.11 & $0.001^{\star \star \star}$ & $0.16,0.62$ & 0.32 & 0.11 & $0.001^{\star \star \star}$ & $0.16,0.63$ & 0.34 & 0.12 & $0.003^{\star \star}$ & $0.17,0.68$ & 0.30 & 0.11 & $0.001^{\star \star \star}$ & $0.14,0.62$ \\
\hline \multicolumn{17}{|l|}{ Main job: } \\
\hline $\begin{array}{l}\text { Other positions } \\
\text { (Ref.) }\end{array}$ & 1.00 & & & & 1.00 & & & & 1.00 & & & & 1.00 & & & \\
\hline White-collar jobs & 0.44 & 0.17 & $0.033^{*}$ & $0.20,0.93$ & 0.44 & 0.17 & $0.036^{\star}$ & $0.20,0.95$ & 0.49 & 0.20 & 0.074 & $0.23,1.07$ & 0.62 & 0.26 & 0.255 & $0.28,1.40$ \\
\hline Missing & 0.41 & 0.25 & 0.151 & $0.12,1.38$ & 0.41 & 0.26 & 0.156 & $0.12,1.40$ & 0.38 & 0.24 & 0.126 & $0.11,1.31$ & 0.35 & 0.23 & 0.102 & $0.10,1.23$ \\
\hline \multicolumn{17}{|c|}{ Social participation and contacts: } \\
\hline $\begin{array}{l}\text { Lower frequency } \\
\text { (Ref.) }\end{array}$ & - & - & - & - & 1.00 & & & & 1.00 & & & & 1.00 & & & \\
\hline Higher frequency & - & - & - & - & 0.81 & 0.36 & 0.636 & $0.34,1.92$ & 0.84 & 0.38 & 0.702 & $0.35,2.02$ & 0.79 & 0.36 & 0.608 & $0.32,1.93$ \\
\hline
\end{tabular}




\section{Discussion}

In this paper, we were able to develop further, and apply, the full multi-step conceptual model for the study of selective participation as elaborated in Poli et al. (2019) and partially applied in Poli et al. (2020). Following that conceptualisation of selective participation, we were able to isolate the different steps of selection (i.e. pre-screening, recruitment and self-selection), to describe them, and to investigate in more detail self-selection based on both recruitment data and individual survey information. We aimed to understand the involvement of older people in the evaluation of digital health technologies for self-care as a multi-step process from project recruitment to the individual decision to participate (i.e. self-selection) and its association with socio-demographic indicators, health, social participation and technology familiarity. This was studied within MIRAS which evaluated a Web-based mobile phone system for monitoring post-operative progress of patients undergoing day surgery. MIRAS intervention outcomes were not of interest for this specific work.

Our results show that some groups of individuals are less likely to participate in digital health research. Participation is selective as a result of selections occurring in the pre-screening, recruitment and self-selection steps. Increasing age enhanced the likelihood of being non-screened, non-recruited or decliner, and those who were non-recruited were most often ineligible because of technology-related barriers.

As regards self-selection, we show that decliners and participants differed in regard to age, gender, job, health status and digital skills, but did not differ by the level of social participation. However, we cannot confirm the impact of the main job when considering health status and digital skills as well.

In line with our hypothesis, belonging to a younger age group increased the likelihood of accepting an invitation to participate in MIRAS. This agrees with previous studies (Mair et al., 2006; Broendum et al., 2016; Poli et al., 2020). Also, being female increased the probability of accepting an invitation to participate. This supports what has been found in other studies that focus generally on participation in research (Glass et al., 2015; Yang et al., 2017) but contrasts with previous findings which reported that females were more likely to decline than men (Broendum et al., 2016) or there were no differences (Mair et al., 2006; Poli et al., 2020). We also found that job predicted the decision to participate. Participants were more likely to indicate a white-collar job compared to decliners. This is in line with our hypothesis and can be explained by the fact that white-collar workers' activities usually involve the use of digital technologies to a greater extent than other jobs, which predisposes white-collar workers and former white-collar workers to be more willing to use digital technologies outside their job (König et al., 2018). It is also in agreement with previous studies that describe those who volunteer to participate in digital health research as having a higher socio-economic status (van Heuvelen et al., 2005; Green et al., 2011; Gaertner et al., 2016) than those who refuse to participate.

In accordance with our hypothesis and previous findings (Broendum et al., 2016), individuals reporting better health status showed a higher probability of accepting an invitation to participate in MIRAS. This contrasts with the results of a previous study (Poli et al., 2020) in which we did not find any health effect 
on the decision to participate. However, that result was most likely quite specific and due to the fact that individuals with poor health status were excluded in the early phases of the recruitment process (due to exclusion criteria) and, therefore, did not receive an invitation to participate and did not have the chance to participate.

Higher levels of digital skills predicted the individual decision to participate in MIRAS. This result confirms our hypothesis and adds to previous studies which found that older decliners were more likely to be computer non-users (Dodge et al., 2014) and more often reported technical concerns as a reason for declining to participate (Broendum et al., 2016). Also, it agrees with the findings of other studies that involved broader target populations than older people (Palmas et al., 2006; Foster et al., 2015).

Our results suggest that some older people, in particular, are less likely to be involved in digital health research relative to their counterparts. Being conceived and evaluated by highly selected groups of older individuals, the new digitalbased services can result in not being properly accessible and usable for those older people who are typically neglected in digital health research. With more digital health research being conducted, and digital-based care provision expanding rapidly and expected to increase (Ekman et al., 2019), this can translate into an increased risk of exclusion from digital technology and relevant resources and services for some groups of older people, further widening old-age inequalities.

We, therefore, argue that self-selection in digital health research can work as a driver of exclusion and contribute to inequalities among older people through selective non-participation and poor involvement. It limits the understanding of old-age diversity and prevents some groups of older individuals from influencing the evaluation of future services which are intended to address their needs. Those groups of older people who are less likely to be involved in digital health research may show more negative or more positive intervention outcomes compared to those who are more likely to participate. This would produce insufficient research outcomes which incorrectly inform digitalisation policies and practice.

This study has some limitations. First, the response rate to the survey study among decliners was 24 per cent. This reduced the amount of information available on decliners for use in the analyses and could have diminished or increased some predictors' effects on the individual decision to participate. Second, reasons for declining to participate were not available. Such reasons would have further detailed the individual decision not to participate in MIRAS. Similarly, third, reasons for non-screening were not available. Having access to such reasons would have allowed a more comprehensive interpretation of the exclusion of some older individuals from even entering the recruitment phase. Fourth, women represented a larger group in the overall sample than men. This could be due to the fact that some of the eligible day surgeries for the MIRAS project mostly targeted women (e.g. breast cancer surgery). Fifth, information on the types of surgery was unsystematically collected and could not be used in the analyses. Type of surgery may be a further factor influencing self-selection as it exposes the individuals to different post-operative experiences and recovery time-frames. Depending on type of 
surgery, some individuals may be more or less prone to take part in an intervention study after day surgery.

Nevertheless, this study provides strong evidence that digital health research should focus more attention on self-selection and the resulting selective nonparticipation. First, selective involvement of older people in digital health research should be taken into account when conceptualising old-age digital exclusion and defining its underlying mechanisms. Indeed, the non-use of digital technologies can derive from poor inclusivity in evaluation phases of new digital-based services which prevents some older people from influencing both the research results and resultant conclusions. Second, research should identify what strategies can be implemented to make the recruitment processes more inclusive towards those individuals who are more likely to be excluded from participating in digital health studies, and to improve evaluation results. Third, the study of self-selection and other selection processes needs to go beyond relying only on recruitment and registry information. Our results show the importance of including the individual perspective on participation and non-participation, and provides a more comprehensive picture of the existing selectivity of older people in digital health research. However, collecting information on non-participants remains challenging, therefore future studies should invest in understanding how to improve existing instruments as well as data collection strategies. Finally, our findings are relevant beyond digital health and can be extended to other fields of research in which innovative interventions for older people are evaluated.

Author contributions. All authors have given their final approval of the version to be published and made a substantial contribution to the conception and design, or analysis and interpretation of data, and the drafting of the article or revising the manuscript critically for important intellectual content.

Financial support. This work and the MIRAS project were conducted as part of 'Supporting Self-care by Information and Communication Technology for Older People with Long-term Conditions' (ICT4SELFCARE) funded by the Swedish Research Council for Health, Working Life and Welfare (FORTE) (reference number 2014-4100).

Conflict of interest. The authors declare no conflicts of interest.

Ethical standards. Ethical approval was granted by the competent Regional Ethical Review Board in Linköping (dnrs 2014/422-31 and 2016/474-31).

\section{References}

Allemann H and Poli A (2020) Designing and evaluating information and communication technologybased interventions? Be aware of the needs of older people. European Journal of Cardiovascular Nursing 19, 370-372.

Aner K (2016) Discussion paper on participation and participatory methods in gerontology. Zeitschrift für Gerontologie und Geriatrie 49, 153-157.

Baron J, Hirani S and Newman S (2015) Challenges in patient recruitment, implementation, and fidelity in a mobile telehealth study. Telemedicine and e-Health 22, 400-409.

Bennett DA (2001) How can I deal with missing data in my study? Australian and New Zealand Journal of Public Health 25, 464-469.

Berridge C and Wetle TF (2019) Why older adults and their children disagree about in-home surveillance technology, sensors, and tracking. The Gerontologist 60, 926-934. 
Boise L, Wild K, Mattek N, Ruhl M, Dodge HH and Kaye J (2013) Willingness of older adults to share data and privacy concerns after exposure to unobtrusive in-home monitoring. Gerontechnology 11, 428435.

Broendum E, Ulrik CS, Gregersen T, Hansen EF, Green A and Ringbaek T (2016) Barriers for recruitment of patients with chronic obstructive pulmonary disease to a controlled telemedicine trial. Health Informatics Journal 24, 216-224.

Chen L-K (2020) Gerontechnology and artificial intelligence: better care for older people. Archives of Gerontology and Geriatrics 91, 104252.

Corregidor-Sánchez AI, Segura-Fragoso A, Rodríguez-Hernández M, Jiménez-Rojas C, Polonio-López B and Criado-Álvarez JJ (2020) Effectiveness of virtual reality technology on functional mobility of older adults: systematic review and meta-analysis. Age and Ageing 50, 370-379.

Coughlin JF (2020) The fourth wave of technology and aging: policy innovation to ensure equity and inclusion. Public Policy \& Aging Report 30, 138-141.

Czaja SJ (2017) The potential role of technology in supporting older adults. Public Policy \& Aging Report 27, 44-48.

Czaja SJ, Boot WR, Charness N and Rogers WA (2019) Designing for Older Adults: Principles and Creative Human Factors Approaches. Boca Raton, FL: CRC Press.

Dodge HH, Katsumata Y, Zhu J, Mattek N, Bowman M, Gregor M, Wild K and Kaye JA (2014) Characteristics associated with willingness to participate in a randomized controlled behavioral clinical trial using home-based personal computers and a webcam. Trials 15, 508.

Eccles A (2021) Remote care technologies, older people and the social care crisis in the United Kingdom: a Multiple Streams Approach to understanding the 'silver bullet' of telecare policy. Ageing \& Society 41, $1726-1744$.

Ekman B, Thulesius H, Wilkens J, Lindgren A, Cronberg O and Arvidsson E (2019) Utilization of digital primary care in Sweden: descriptive analysis of claims data on demographics, socioeconomics, and diagnoses. International Journal of Medical Informatics 127, 134-140.

European Commission (2018) Communication from the Commission to the European Parliament, the Council, the European Economic and Social Committee and the Committee of the Regions on Enabling the Digital Transformation of Health and Care in the Digital Single Market; Empowering Citizens and Building a Healthier Society. Available at https://eur-lex.europa.eu/legal-content/EN/TXT/?uri=COM\% 3A2018\%3A233\%3AFIN.

European Commission (2020) Digital Economy and Society Index (DESI) 2020 - Sweden. Available at https://ec.europa.eu/newsroom/dae/document.cfm?doc_id=66932.

Foster A, Horspool KA, Edwards L, Thomas CL, Salisbury C, Montgomery AA and O'Cathain A (2015) Who does not participate in telehealth trials and why? A cross-sectional survey. Trials 16, 258.

Gaertner B, Seitz I, Fuchs J, Busch MA, Holzhausen M and Martus P (2016) Baseline participation in a health examination survey of the population 65 years and older: who is missed and why? BMC Geriatrics $16,21$.

Gallistl V, Rohner R, Seifert A and Wanka A (2020) Configuring the older non-user: between research, policy and practice of digital exclusion. Social Inclusion 8, 233-243.

Gell NM, Rosenberg DE, Demiris G, LaCroix AZ and Patel KV (2015) Patterns of technology use among older adults with and without disabilities. The Gerontologist 55, 412-421.

Glass DC, Kelsall HL, Slegers C, Forbes AB, Loff B, Zion D and Fritschi L (2015) A telephone survey of factors affecting willingness to participate in health research surveys. BMC Public Health 15, 1017.

Green BB, Anderson ML, Ralston JD, Catz S, Fishman PA and Cook AJ (2011) Patient ability and willingness to participate in a web-based intervention to improve hypertension control. Journal of Medical Internet Research 13, e1.

Hargittai E, Piper AM and Morris MR (2019) From internet access to internet skills: digital inequality among older adults. Universal Access in the Information Society 18, 881-890.

Kandola DK, Banner D, Araki Y, Bates J, Hadi H and Lear SA (2018) The Participant Recruitment Outcomes (PRO) study: exploring contemporary perspectives of telehealth trial non-participation through insights from patients, clinicians, study investigators, and study staff. Contemporary Clinical Trials Communications 11, 75-82.

Kim TK and Choi M (2019) Older adults' willingness to share their personal and health information when adopting healthcare technology and services. International Journal of Medical Informatics 126, 86-94. 
König R, Seifert A and Doh M (2018) Internet use among older Europeans: an analysis based on SHARE data. Universal Access in the Information Society 17, 621-633.

Lüders M and Brandtzæg PB (2014) 'My children tell me it's so simple': a mixed-methods approach to understand older non-users' perceptions of Social Networking Sites. New Media \& Society 19, 181-198.

Mair FS, Goldstein P, Shiels C, Roberts C, Angus R, O'Connor J, Haycox A and Capewell S (2006) Recruitment difficulties in a home telecare trial. Journal of Telemedicine and Telecare 12, 26-28.

Matthews K, Nazroo J and Marshall A (2019) Digital inclusion in later life: cohort changes in internet use over a ten-year period in England. Ageing \& Society 39, 1914-1932.

Merkel S and Kucharski A (2018) Participatory design in gerontechnology: a systematic literature review. The Gerontologist 59, e16-e25.

Mitchell M and Kan L (2019) Digital technology and the future of health systems. Health Systems \& Reform 5, 113-120.

Mitchell UA, Chebli PG, Ruggiero L and Muramatsu N (2018) The digital divide in health-related technology use: the significance of race/ethnicity. The Gerontologist 59, 6-14.

Olsson T, Samuelsson U and Viscovi D (2019) At risk of exclusion? Degrees of ICT access and literacy among senior citizens. Information, Communication \& Society 22, 55-72.

Palmas W, Teresi J, Morin P, Wolff LT, Field L, Eimicke JP, Capps L, Prigollini A, Orbe I and Weinstock RS (2006) Recruitment and enrollment of rural and urban medically underserved elderly into a randomized trial of telemedicine case management for diabetes care. Telemedicine and e-Health 12, 601-607.

Pérez Sust P, Solans O, Fajardo JC, Medina Peralta M, Rodenas P, Gabaldà J, Garcia Eroles L, Comella A, Velasco Muñoz C, Sallent Ribes J, Roma Monfa R and Piera-Jimenez J (2020) Turning the crisis into an opportunity: digital health strategies deployed during the COVID-19 outbreak. JMIR Public Health and Surveillance 6, e19106.

Poli A, Kelfve S and Motel-Klingebiel A (2019) A research tool for measuring non-participation of older people in research on digital health. BMC Public Health 19, 1487.

Poli A, Kelfve S, Klompstra L, Strömberg A, Jaarsma T and Motel-Klingebiel A (2020) Prediction of (non)participation of older people in digital health research: exergame intervention study. Journal of Medical Internet Research 22, e17884.

Poli A, Kostakis I and Barbabella F (2021) Receiving care through digital health technologies: drivers and implications of old-age digital health exclusion. In Walsh K, Scharf T, Van Regenmortel S and Wanka A (eds), Social Exclusion in Later Life-Interdisciplinary and Policy Perspectives. Cham, Switzerland: Springer, pp. 169-181.

Robinson L, Cotten SR, Ono H, Quan-Haase A, Mesch G, Chen W, Schulz J, Hale TM and Stern MJ (2015) Digital inequalities and why they matter. Information, Communication of Society 18, 569-582.

Schafer JL (1999) Multiple imputation: a primer. Statistical Methods in Medical Research 8, 3-15.

Schulz R, Wahl H-W, Matthews JT, De Vito Dabbs A, Beach SR and Czaja SJ (2015) Advancing the aging and technology agenda in gerontology. The Gerontologist 55, 724-734.

Seifert A (2020) The digital exclusion of older adults during the COVID-19 pandemic. Journal of Gerontological Social Work 63, 674-676.

Statista (2021) Share of the population with access to the internet at home in Sweden from 2009 to 2019. Internet, Demographics \& Use. Available at https://www.statista.com/statistics/543324/sweden-access-tothe-internet/.

Terraneo M (2015) Inequities in health care utilization by people aged 50+: evidence from 12 European countries. Social Science \& Medicine 126, 154-163.

van Heuvelen MJG, Hochstenbach JBM, Brouwer WH, de Greef MHG, Zijlstra GAR, van Jaarsveld E, Kempen GIJM, van Sonderen E, Ormel J and Mulder T (2005) Differences between participants and non-participants in an RCT on physical activity and psychological interventions for older persons. Aging Clinical and Experimental Research 17, 236-245.

Wyatt SM (2003) Non-users also matter: the construction of users and non-users of the Internet. In Oudshoorn N and Pinch $\mathrm{T}$ (eds), How Users Matter: The Co-construction of Users and Technology. Cambridge, MA: MIT Press, pp. 67-79.

Yang R, Carter BL, Gums TH, Gryzlak BM, Xu Y and Levy B (2017) Selection bias and subject refusal in a cluster-randomized controlled trial. BMC Medical Research Methodology 17, 94. 
Yoon H, Jang Y, Vaughan PW and Garcia M (2018) Older adults' Internet use for health information: digital divide by race/ethnicity and socioeconomic status. Journal of Applied Gerontology 39, 105-110.

Cite this article: Poli A, Kelfve S, Berg K, Motel-Klingebiel A (2021). Old-age diversity is underrepresented in digital health research: findings from the evaluation of a mobile phone system for post-operative progress monitoring in Sweden. Ageing \& Society 1-23. https://doi.org/10.1017/S0144686X21001641 